\title{
Telerehabilitation for Communication and Swallowing Disorders in Parkinson's Disease
}

\author{
Deborah Theodoros* \\ School of Health and Rehabilitation Sciences, The University of Queensland, Brisbane, QLD, Australia
}

Accepted 1 March 2021

Pre-press 19 April 2021

\begin{abstract}
Communication and swallowing disorders are highly prevalent in people with Parkinson's disease (PD). The negative impact of these disorders on the quality of life of the person with PD and their families cannot be underestimated. Despite a demand for speech-language pathology services to support people with PD, many barriers to services exist. Telerehabilitation provides an alternate and complementary approach to in-person therapy that is patient-centered, enables timely assessment and intervention, and facilitates continuity of care throughout the course of the disease. This review explores the telerehabilitation applications designed for the management of the communication and swallowing disorders in PD, addresses the benefits and challenges of telerehabilitation, identifies future research directions, and highlights the potential of new technologies to enhance the management of communication and swallowing disorders and quality of life for people with PD.
\end{abstract}

Keywords: Dysarthria, language disorders, Parkinson's disease, speech-language pathology, swallowing disorders, telerehabilitation

\section{COMMUNICATION AND SWALLOWING DISORDERS}

Communication and swallowing disorders are common sequelae of Parkinson's disease (PD) with the prevalence and severity increasing as the disease progresses. The communication disorders include the speech disorder, hypokinetic dysarthria, and a cognitive-communicative language disorder associated with cognitive decline [1,2]. Dysarthria, evident in up to $89 \%$ of people with PD (PWP) is characterized by imprecise articulation, reduced loudness, monotony of pitch and loudness, short rushes

\footnotetext{
${ }^{*}$ Correspondence to: Emeritus Professor Deborah Theodoros, School of Health and Rehabilitation Sciences, The University of Queensland, St Lucia 4072, Brisbane, Queensland, Australia. Tel.: +61 7411090 681; E-mail: d.theodoros@uq.edu.au.
}

of speech/accelerated speech, a breathy and harsh vocal quality, and reduced breath support for speech $[1,3]$. Cognitive changes associated with PD range from mild cognitive impairment (up to $33 \%$ ) through to dementia (24\% to $31 \%$ ) [4]. These cognitive changes impact attention, episodic and working memory, and executive functions which underpin the comprehension and expression of language $[2,5]$. The associated cognitive-communication disorders include: impaired comprehension of long and complex sentences and paragraph text [6,7]; difficulty in interpreting abstract language and humor [8]; and impairment of word-finding and verbal fluency [9]; and sentence production [10].

Swallowing disorders (dysphagia) occur in $80 \%$ of PWP when objectively measured despite self-reported dysphagia evident in only one-third of PWP living in the community [11]. As swallowing disorders 
increase with age, disease duration and dementia [12], effective monitoring and timely management of swallowing function is imperative in PWP. Swallowing abnormalities include: decreased oral control of the bolus; lingual pumping to execute the swallow; delayed initiation of pharyngeal swallow; slow laryngeal elevation and excursion; and upper esophageal sphincter incoordination [13]. Swallowing dysfunction may result in drooling [14], oral residue postswallow [15], and bolus penetration and aspiration [16]. Aspiration occurs in more than 50\% of PWP and may be obvious or silent $[17,18]$. Videofluroscopic examination of swallowing is required to determine the safety of oral intake [17].

\section{NEED FOR ACCESSIBLE SUPPORT}

People with PD and their families convincingly report the negative impact of communication and swallowing disorders on their quality of life. The speech and cognitive-communication disorders result in ineffective social communication due to difficulties in being understood, expressing personal opinions, and initiating topics in conversation [19-22]. Swallowing disorders result in embarrassment when eating and drinking, and anxiety regarding choking and drooling $[19,22]$. The communication and swallowing disorders lead to reduced confidence, social withdrawal, isolation, low levels of communicative participation in everyday life and a poorer quality of life [22-24].

Maintaining quality of life and adequate levels of functional communication and swallowing throughout the course of the disease is challenging for both PWP and their families, and speech-language pathologists (SLPs). Although SLPs provide effective intervention to PWP, in-person service delivery and established processes preclude a sustainable longterm approach to management. Access to SLP services for PWP remains inadequate with studies in western countries reporting only $45 \%$ to $59 \%$ of PWP receiving varying levels of service [19, 22, 25]. Common barriers to accessing SLP services include: geographical location; availability of clinicians with PD-specific expertise; motor, cognitive, communication, and psychological disturbances associated with PD; timing of medications; and dependency on others to attend healthcare facilities [19, 21, 22].

What is needed is an equitable and flexible alternate service delivery model that mitigates these barriers and addresses the communication and swallowing needs of PWP in a timely manner. The impetus for change in SLP service models is supported by emerging social, economic and healthcare imperatives indicating a rise in PD with increased life expectancy [26], the desire of older people to remain living in their own homes [27] and the move towards integrated and patient-centered management involving care close to home, patient empowerment and self-management, proactive and timely care, tailored interventions, access to appropriate care, coordinated care management, and continuity of care for PWP [28].

This short review paper provides a summary of research in the management of the communication and swallowing disorders in people with PD via telerehabilitation for health professionals working with PWP. It highlights key findings from a previous systematic review [29].

\section{TELEREHABILITATION}

Telerehabilitation in which various technologies are used to deliver rehabilitation at a distance [30] provides an alternate and complementary approach to the management of the communication and swallowing disorders in PD. Professional associations in the USA [31], United Kingdom [32] and Australia [33] endorse the use of telerehabilitation/telepractice as a mode of service delivery in speech-language pathology and provide training and resources for clinicians. Preservice training programs for SLPs in telerehabilitation have been established in university-based clinics [34, 35].

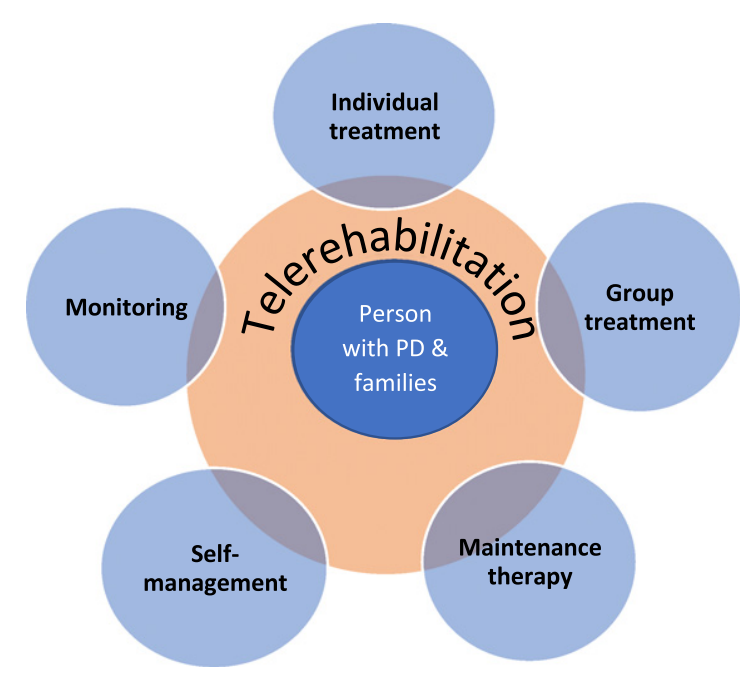

Fig. 1. Telerehabilitation and the Management of Communication and Swallowing Disorders in Parkinson's Disease. 
Technology can support an ongoing home-based patient-centered management program for communication and swallowing disorders involving tailored individual treatment, group therapy, maintenance therapy, self-management, and monitoring throughout the course of the disease (See Fig. 1).

An example for a PWP with a speech disorder:

A PWP receives intensive individual treatment via videoconferencing; exercises self-management of their speech through home practice with computerbased software and mobile apps; participates in group therapy via multipoint videoconferencing; connects regularly with the SLP via videoconference to receive booster therapy to maintain speech; engages in periodic monitoring of speech by sending audio/video recorded speech samples via email to SLP for review and feedback.

A systematic scoping review identified 15 studies involving the technology-enabled management of communication and swallowing disorders in PWP [29]. The research focused on the assessment and treatment of the speech disorder with little attention given to the management of cognitive-communication disorders. The technologies involved in these studies included both synchronous and asynchronous tools such as videoconferencing software, computer-based software, a web-based application, and remote monitoring via a smartphone. To date, rigorous validation of online assessment of the speech disorder in PD has been reported using videoconferencing [36]. Treatment studies have focused on the delivery of the intensive, LSVT LOUD ${ }^{\circledR}$ program [37, 38] and demonstrated the noninferiority of this treatment when delivered via telerehabilitation [39-41]. An extended version of this treatment (LSVT-X) [42] has been shown to be efficacious when delivered via videoconferencing [43]. Computer-based software, LSVT Companion ${ }^{\circledR}$, provides an asynchronous technology for use by the PWP in the home to engage in the LSVT LOUD program and to maintain speech [44]. Online group therapy for PWP following LSVT LOUD has been found to be feasible and acceptable to PWP as a form of maintenance therapy using multipoint videoconferencing software [45]. A self-management asynchronous web-based application (e-learning-based speech therapy - EST) in combination with phone and email contact demonstrated improved speech intelligibility in a single case of a PWP [46]. One case study reported on the feasibility of remote monitoring of speech and language in PWP via a smartphone in which small sensors recorded voice and language [47].
To date only one study has investigated the validity and reliability of assessing cognitive-communication function in PWP via videoconferencing (Swales et al, unpublished data). High strength of agreement between online and in-person raters was identified for all subtests of the Montreal Cognitive Assessment [48], four subtests of the Boston Diagnostic Aphasia Examination-3 [49], and the Mt Wilga High-Level Language Test [50].

The use of telerehabilitation to address the swallowing disorders in PWP has focused primarily on clinical assessment of swallowing via videoconferencing. Seminal research in this area demonstrated the validity, reliability and acceptability of online swallowing assessment in cohorts including PWP and other conditions [51, 52]. Videofluoroscopic assessment of swallowing in various cohorts has been found to be valid and reliable in the online environment and has potential to identify silent aspiration in PWP [53, 54]. Although specific validation studies involving treatment have yet to be conducted, telerehabilitation offers the opportunity for SLPs to observe PWP in their usual environment during meals and offer advice and direction regarding positioning, food intake, and safety considerations. The realism achieved through viewing the PWP in the home at mealtimes via videoconferencing surpasses the simulated in-clinic approach and supports the use of telerehabilitation in the management of swallowing disorders in PD.

The acceptance of telerehabilitation by PWP and their families is essential for integration of this mode of service delivery into mainstream practice. Overall, PWP and their families have expressed support for technology-enabled services and acceptance of technology, and an appreciation of the benefits of this service mode [29].

Despite the benefits and acceptability of telerehabilitation for PWP and their families, there are some challenges in delivering effective online services to PWP. Key challenges include: patient factors; e-helper training; type and availability of technology; access to online resources; and reimbursement. The use of telerehabilitation for PWP is dependent on the patient having sufficient cognitive function to follow instructions and retain information, adequate aided hearing and vision, and the availability of assistance on their end when needed. Appropriate selection of PWP for telerehabilitation is critical to success and may not always be achieved through screening assessments. In some cases, it is necessary to conduct a trial session/s with a PWP to determine suitability. For PWP with cognitive-communication disorders, 
Table 1

Summary of Telerehabilitation for Communication and Swallowing Disorders in Parkinson's Disease (PD)

- Telerehabilitation is feasible and valid for management of speech disorder

- Online assessment of swallowing disorders validated

- Treatment of cognitive-communication and swallowing disorders

via telerehabilitation yet to be validated

- Accepted by people with PD and families

- Patient-centered, e.g., local point of delivery, tailored to individual needs

- Facilitates timely and proactive intervention throughout course of the disease

- Enables flexible use of multiple forms of intervention,

e.g., individual, group or maintenance therapy, self-management, monitoring

additional language and memory supports will be required to facilitate therapy sessions. E-helper training is essential for remote clinical swallowing assessments to ensure the safety of the procedure [55]. The e-helper must be trained to deliver the oral intake, monitor the swallow, and provide feedback to the online clinician.

The type and availability of technology (devices and internet connectivity) may present as a barrier for some PWP depending on cost and location. Where internet connectivity and technology is suboptimal such that service fidelity cannot be maintained, telerehabilitation should not be considered. The functionality of the technology to deliver a service needs to be carefully considered by the clinician. For example, to effectively deliver LSVT LOUD, the technology must provide videoconferencing, have capacity to record sound pressure level and frequency of the voice, and be able to provide audio playback of speech samples for the PWP to self-monitor.

Clinicians must also consider the availability of online assessment and therapy resources to execute their management plans. Some standardized assessments may not yet be available in digital format, and time and funds are needed to develop online therapy resources. Reimbursement for services has been a universal barrier but may become less so in the future following recent expansion of reimbursement to speech pathology services during the COVID-19 pandemic. However, the challenge to maintain ongoing reimbursement remains.

\section{THE FUTURE}

With research to date focused predominantly on the management of the speech disorder via telerehabilitation, future research needs to address the treatment of cognitive-communication and swallowing disorders to provide a comprehensive telerehabilitation management plan for PWP. Integration of telerehabilitation into mainstream practice will require implementation research addressing changes to administrative and clinical processes, clinician training, and cost analyses.

Although videoconferencing software has been the main telerehabilitation tool used to date, technologies such as asynchronous web-based portals, specific remote monitoring technologies, virtual reality (VR), and artificial intelligence (AI) are likely to contribute to the management of communication and swallowing disorders in PWP in the future. Web-based portals enable clinicians to design tailored home therapy programs for patients, track adherence, and monitor performance remotely [56], and provide more consistent self-management and maintenance support. Remote monitoring technology specifically for oropharyngeal swallowing disorders is also being developed and may be beneficial for PWP [57]. Virtual reality can provide immersive simulated realworld environments in which PWP can practice everyday communicative situations (e.g., ordering in a restaurant, conversing in distracting environments) in a supportive setting [58]. The VR scenarios also enable more ecologically valid assessments and interventions beyond the clinic interaction [58]. Artificial intelligence involving machine learning and natural language processing has the potential to develop speech recognition software for PWP enabling more accurate diagnosis and monitoring of the disorder [59] and ultimately, access to in-home communication assistant devices.

\section{CONCLUSION}

Telerehabilitation is a feasible and valid mode of service delivery for the management of the speech disorder associated with PD and for the assessment of swallowing. The treatment of cognitivecommunication and swallowing disorders via telerehabilitation has yet to be validated. Telerehabilitation enables patient-centered care in the person's natural environment thus optimizing therapeutic benefits 
and facilitates timely intervention across the course of the disease. The acceptance and acknowledged benefits of telerehabilitation by PWP bodes well for integration into mainstream SLP practice (Table 1). The ongoing development of technology will result in the availability of more sophisticated applications to effectively assess and treat communication and swallowing disorders and improve the quality of life of PWP and their families.

\section{CONFLICT OF INTEREST}

The author has no conflict of interest to report.

\section{REFERENCES}

[1] Duffy JF (2013) Hypokinetic Dysarthria. In Motor speech disorders: Substrates, differential diagnosis, and management, Duffy JF. ed. Elsevier Mosby. St Louis, pp. 165-189.

[2] Hancock A, La Pointe L, Whelan B-M (2011) Cognitivelinguistic disorder in Parkinson disease. In Communication and Swallowing in Parkinson Disease, Theodoros D, Ramig L, eds. Plural Publishing, San Diego, pp. 123-178.

[3] Hartelius L, Svensson P (1994) Speech and swallowing symptoms associated with Parkinson's disease and multiple sclerosis: A survey. Folia Phoniatr Logop 46, 9-17.

[4] Santangelo G, Vitale C, Picello M, Moccia M, Cuoco S, Lingo K, Pezzella D, di Grazia A, Erro R, Pellecchia M, Amboni M, Trojano L, Barone P (2015) Mild cognitive impairment in newly diagnosed Parkinson's disease: A longitudinal prospective study. Parkinsonism Relate Disord 21, 1219-1226.

[5] Pfeiffer HCV, Lokkegaard A, Zoetmulder M, Friberg L, Werdelin L (2014) Cognitive impairment in early-stage nondemented Parkinson's disease patients. Acta Neurol Scan 129, 307-318.

[6] Colman KS, Koerts J, Stowe LA, Leenders KL, Bastiaanse $\mathrm{R}$ (2011) Sentence comprehension and its association with executive functions in patients with Parkinson's disease. Parkinsons Dis 2011, 213983.

[7] Murray LL, Rutledge S (2014) Reading comprehension in Parkinson's disease. Am J Speech Lang Pathol 23, S246S258.

[8] Monetta L, Grindrod CM, Pell MD (2009) Irony comprehension and theory of mind deficits in patients with Parkinson's disease. Cortex 45, 972-981.

[9] Burdick DJ, Cholerton B, Watson GS, Siderowf JQ, Trojanowski D, Weintraub B, Ritz SL, Edwards, KL, Montine TJ, Zabetian CP, Leverenz JB (2014) People with Parkinson's disease and normal MMSE score have a broad range of cognitive performance. Mov Disord 29, 1258-1264.

[10] Troche MS, Altman LJP (2012) Sentence production in Parkinson disease: Effects of conceptual and task complexity. App Psycholinguist 33, 225-251.

[11] Kalf JG, De Swart BJM, Bloem BR, Munneke M (2012) Prevalence of oropharyngeal dysphagia in Parkinson's disease: A meta-analysis. Parkinsonism Relat Disord 18, 311-315.

[12] Cereda E, Cilia R, Klersy C, Canesi M, Zecchinelli AL, Mariani CB, Tesei S, Sacilotto G, Meucci N, Zini M, Isaias IU, Cassani E, Goldwurm S, Barichella M, Pezzoli G
(2014) Swallowing disturbances in Parkinson's disease: A multivariate analysis of contributing factors. Parkinsonism Relat Disord 20, 1382-1387.

[13] Troche MS, Sapienza CM, Rosenbek JC (2008) Effects of bolus consistency on timing and safety of swallow in patients with Parkinson's disease. Dysphagia 23, 26-32.

[14] Srivanitchapoom P, Pandey S, Hallett M (2014) Drooling in Parkinson's disease: A review. Parkinsonism Relat Disord 20, 1109-1118.

[15] Miller N, Noble E, Jones D, Burn D (2006) Hard to swallow: Dysphagia in Parkinson's disease. Age Ageing 35, 614-618.

[16] Mehanna R, Jankovic J (2010) Respiratory problems in neurologic movement disorders. Parkinsonism Relat Disord 16, 628-638.

[17] Argolo N, Sampaio M, Pinho P, Melo A, Nobrega AC (2015) Videofluoroscopic predictors of penetration-aspiration in Parkinson's disease patients. Dysphagia 30, 751-758.

[18] Rodrigues B, Nobrega AC, Sampaio M, Argolo N, Melo A (2010) Silent saliva aspiration in Parkinson's disease. Mov Disord 26, 138-141.

[19] Miller N, Noble E, Jones D, Deane KHO, Gibb C (2011) Survey of speech and language therapy provisions for people with Parkinson's disease in the United Kingdom: Patient's and carers' perspectives. Int J Lang Commun Disord 46, 179-188.

[20] Soundy A, Stubbs B, Roskell C (2014) The experience of Parkinson's disease: A systematic review and metaethnography. Scientific WorldJournal 2014, 613592.

[21] Spurgen L, Clarke CE, Sackley C (2015) Subjective experiences of speech and language therapy in patients with Parkinson's Disease: A pilot study. Rehabil Res Pract 2015, 839895

[22] Swales M, Theodoros D, Hill AJ, Russell T (2020) Communication and swallowing changes, everyday impacts and access to speech-language pathology services for people with Parkinson's disease: An Australian survey. Int J Speech Lang Pathol, doi: 10.1080/17549507.2020.1739332

[23] McAuliffe MJ, Baylor CR, Yorkston KM (2017) Variables associated with communicative participation in Parkinson's disease and its relationship to measures of health-related quality-of-life. Int J Speech Lang Pathol 19, 407-417.

[24] Takahash, K, Kamide N, Suzuki M, Fukuda M (2016) Quality of life in people with Parkinson's disease: The relevance of social relationships and communication. J Phys Ther Sci 28, 541-546.

[25] Schalling S, Johansson K, Hartelius L (2017) Speech and communication changes reported by people with Parkinson's Disease. Folia Phoniatr Logop 69, 131-141.

[26] Dorsey ER, Constantinescu R, Thompson JP, Biglan KM, Holloway RG, Kieburtz K, Marshall FJ, Ravina BM, Schifitto G, Siderowf A, Tanner CM (2007) Projected number of people with Parkinson's disease in the most populous nations, 2005 through 2030. Neurology 68, 384-386.

[27] Kahana E, Kahana B (2014) Baby boomers' expectations of health and medicine. Virtual Mentor 16, 380-384.

[28] Bloem BR, Henderson EJ, Dorsey ER, Okun MS, Okubadejo N, Chan P, Andrejack J, Darweesh SKL, Munneke M (2020) Integrated and patient-centered management of Parkinson's disease: A network model for reshaping chronic neurological care. Lancet Neurol 19, 623634.

[29] Theodoros D, Aldridge D Hill, AJ, Russell T (2019) Technology-enabled management of communication and swallowing disorders in Parkinson's disease: A systematic scoping review. Int J Lang Commun Disord 54, 170-188. 
[30] Brennan D, Tyndall L, Theodoros D, Brown J, Campbell M, Christiana D, Smith D, Cason J, Lee A (2011) A blueprint for telerehabilitation guidelines. Telemed J E Health 17, 662-665.

[31] American Speech-Language-Hearing Association. Telepractice. (Practice Portal). www.asha.org/Practice-Portal/Pro fessional-Issues/Telepractice/.

[32] Royal College of Speech Language Therapists. https:// www.rcslt.org/members/delivering-quality-services/teleh ealth/telehealth-guidance/.

[33] Speech Pathology Australia https://www.speechpatholo gyaustralia.org.au/SPAweb/Resources_for_Speech_Pathol ogists/Professional_Resources/HTML/Telepractice.aspx.

[34] Grogan-Johnson S, Meehan R, McCormick K, Miller N (2015) Results of a national survey of preservice telepractice training in graduate speech-language pathology and audiology programs. Contemp Issues Commun Sci Disord 42, 122-137.

[35] University of Queensland Health and Rehabilitation Clinics. https://health-clinics.uq.edu.au/services/telerehabilitation.

[36] Constantinescu G, Theodoros DG, Russell T, Ward EC, Wilson S, Wootton R (2010) Assessing disordered speech and voice in Parkinson's disease: A telerehabilitation application. Int J Lang Commun Disord 45, 630-644.

[37] Levy ES, Moya-Gale G, Chang YM, Freeman K, Forrest K, Brin M, Ramig L (2020) The effects of intensive speech treatment on intelligibility in Parkinson's disease: A randomised controlled trial. EClinicalMedicine 24, 100429.

[38] Ramig LR, Halpern A, Spielman J, Fox C, Freeman K (2018) Speech treatment in Parkinson's disease: Randomized controlled trial (RCT). Mov Disord 33, 1777-1791.

[39] Constantinescu G, Theodoros DG, Russell T, Ward EC, Wilson S, Wootton R (2011) Treating disordered speech and voice in Parkinson's disease online: A randomised controlled non-inferiority trial. Int J Lang Commun Disord 46, 1-16.

[40] Griffin M, Bentley J, Shank, J, Wood C (2018) The effectiveness of Lee Silverman Voice Treatment therapy issued interactively through an iPad device: A non-inferiority study. J Telemed Telecare 24, 209-215.

[41] Theodoros D, Hill A, Russell T (2016) Clinical and quality of life outcomes of speech treatment for Parkinson's disease delivered to the home via telerehabilitation: A noninferiority randomized controlled trial. Am J Speech Lang Pathol 25, 214-232.

[42] Spielman J, Ramig LO, Mahler L, Halpern A, Gavin WJ (2007) Effects of an extended version of the Lee Silverman Voice Treatment on voice and speech in Parkinson's disease. Am J Speech Lang Pathol 16, 95-107.

[43] Dias AE, Limongi JCP, Barbosa ER, Hsing WT (2016) Voice telerehabilitation in Parkinson's disease. Codas 28, 176-181.

[44] Halpern AE, Ramig LO, Matos CEC, Petska-Cable JA, Spielman JL, Pogoda JM, Gilley PM, Sapir S, Bennett JK, McFarland D (2012) Innovative technology for the assisted delivery of intensive voice treatment (LSVT®LOUD) for Parkinson disease. Am J Speech Lang Pathol 21, 354-367.

[45] Quinn R, Park S, Theodoros D, Hill AJ (2019) Delivering group speech maintenance therapy via telerehabilitation to people with Parkinson's disease: A pilot study. Int J Speech Lang Pathol 21, 385-394.
[46] Beijer LJ, Rietveld TCM, Hoskam V, Alexander MA, Guers, $\mathrm{CH}$, De Swart BJM (2010) Evaluating the feasibility and the potential efficacy of e-learning-based speech therapy (EST) as a web application for speech training in dysarthric patients with Parkinson's disease: A case study. Telemed J E Health 16, 732-738.

[47] Chenery HJ, Liddle J, Ireland D, Brauer SG, Theodoros D, Wiles J, McBride S, Karunanithi M, Ding H, Lamont R, Silburn PA (2014) Monitoring the impact of PD on community life using everyday technology: Development of a remote monitoring platform using smartphones. Mov Disord 29, S156-S156.

[48] Nasreddine ZS, Phillips NA, Bedirian V, Charbonneau S, Whitehead V, Collin I, Cummings JL, Chertkow H (2005) The Montreal Cognitive Assessment, MOCA: A brief screening tool for mild cognitive impairment. $J \mathrm{Am}$ Geriatr Soc 53, 695-699.

[49] Goodglass H, Kaplan E, Barresi B (2001) Boston Diagnostic Aphasia Examination ( $3^{\text {rd }}$ ed), Pro-Ed Inc, Austin.

[50] Mt Wilga Private Hospital (2016) Mt Wilga High Level Language Test, Hornsby, New South Wales, Australia.

[51] Sharma S, Ward E, Burns C, Theodoros D, Russell T (2013) Assessing dysphagia via telerehabilitation: Patient perceptions and satisfaction. Int J Speech Lang Pathol 15, 176-183.

[52] Ward EC, Sharma S, Burns C, Theodoros DG, Russell T (2012) Validity of conducting clinical dysphagia assessments for patients with normal to mild cognitive impairment via telerehabilitation. Dysphagia 27, 460-472.

[53] Burns CL, Ward EC, Hill AJ, Phillips N, Porter L (2016) Conducting real-time videofluoroscopic swallow study via telepractice: A preliminary feasibility and reliability study. Dysphagia 31, 473-483.

[54] Malandraki A, Mc Cullough G, He X, McWeeny E, Perlman AL (2011) Teledynamic evaluation of oropharyngeal swallowing. J Speech Lang Hear Res 54, 1497-1505.

[55] Sharma S, Ward E, Burns C, Theodoros D, Russell T (2012) Training the allied health assistant for the telerehabilitation assessment of dysphagia. J Telemed Telecare 18, 287-291.

[56] Van Egmond MA, Engelbert RHH, Klinkenbiil JHG, van Berge Henegouwen MI, van der Schaaf M (2020) Physiotherapy with telerehabilitation in patients with complicated postoperative recovery after esophageal cancer surgery: Feasibility study. J Med Internet Res 22, e16056.

[57] Kim MK, Kantarcigil C, Kim B, Baruah RK, Maity S, Park Y, Kim K, Lee S, Malandraki JB, Avlani S, Smith A, Shreyas S, Alam MA, Malandraki G, Lee CH (2019) Flexible submental sensor patch with remote monitoring controls for management of oropharyngeal swallowing disorders. Sci Adv 5, eaay3210.

[58] Bryant L, Brunner M, Hemsley B (2020) A review of virtual reality technologies in the field of communication disability: Implications for practice and research. Disabil Rehabil Assist Technol 15, 365-372.

[59] Erdogdu Saka B, Serbes G, Sakar CO (2017) Analyzing the effectiveness of vocal features in early telediagnosis of Parkinson's disease. PLoS One 12, e0182428. 